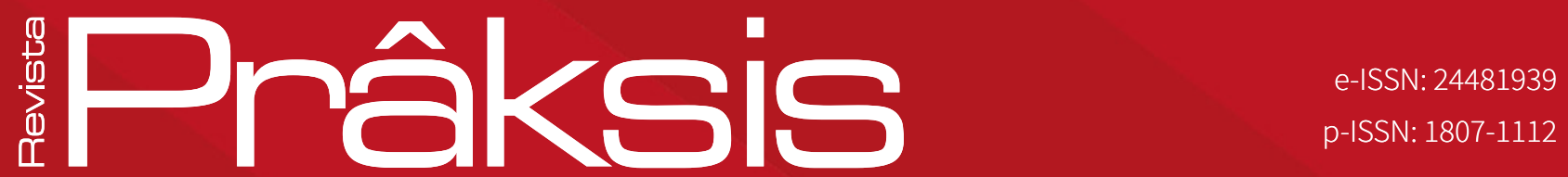

Recebido em: 22 de julho de 2017

Aprovado em: 23 de outubro de 2017

Sistema de Avaliação: Double Blind Review

RPR |a. $15 \mid$ n. 1 | p. 139-152 |jan./jun. 2018

DOI: https://doi.org/10.25112/rpr.v1i0.1308

\title{
EVOLUÇÃO DA EDUCAÇÃO ESPECIAL NO BRASIL, SEGUNDO DEPENDÊNCIA ADMINISTRATIUA
}

\section{EVALUATION OF SPECIAL EDUCATION IN BRAZIL BY ADMINISTRATIVE DEPENDENCE}

\section{Alexandre Dido Balbinot}

Mestre em Saúde Coletiva na Universidade do Vale do Rio dos Sinos (São Leopoldo/ Brasil). Professor no Centro Municipal de Atendimento Educacional Especializado

(Cachoeirinha/Brasil). E-mail: adbalbinot@gmail.com. 


\section{RESUMO}

Introdução: Este estudo objetivou avaliar a evolução do atendimento educacional especializado no Brasil segundo a dependência administrativa das instituições educacionais, utilizando-se como subsídio para a análise dados provenientes do Censo Educacional entre 2005 e 2013. Método: Estudo ecológico que utilizou dados secundários referentes às matrículas realizadas em todo território brasileiro segundo a dependência administrativa das instituições de origem das mesmas. Para análise empregou-se análise descritiva e de frequência, e Regressão Robusta de Poisson. 0 nível de significância utilizado foi de p<0,001. Resultados: Analisou-se 474.365.923 matrículas da educação básica, sendo 6.113.533 de matrículas de educação especial, sendo, 205.262 para rede privada, enquanto que 474.011,4 para rede pública. Houve aumento de 6\% das matrículas da educação especial, sendo $12 \%$ na rede pública e diminuição na rede privada em $6 \%$. Houve aumento nas matrículas das classes comuns do ensino regular para todas as categorias analisadas, sendo $20 \%$ nas matrículas totais, $21 \%$ na rede privada, e $20 \%$ na rede pública. Considerações finais: A educação especial no Brasil tem demonstrado indicativos de estar passado por uma fase de transição, adequando-se aos modelos de atendimento propostos pelos atores sociais implicados na discussão desta temática e sendo impactada principalmente através da educação pública.

Palavras-chave: Educação especial. Dependência administrativa. Inclusão escolar. Brasil.

\section{ABSTRACT}

Introduction: This study aimed to evaluate the evolution of education services in Brazil according to the administrative dependence of educational institutions, using the number of registrations recorded by the educational census between the 2005 and 2013. Method: Ecological study using secondary data in the public domain relating to registrations held throughout Brazil according to the administrative dependence on the same home institutions. For analysis, we used descriptive and frequency analysis, and Regression Poisson Robust. The level of significance was set at $p<0,001$. Results: Analyzed 474.365.923 enrollments in basic education, with 6.113.533 of special education enrollment averaging 679.281,4 per year, and, 205.262 for private network, while 474.011,4 to public. There was a $6 \%$ increase in enrollment of special education, $12 \%$ in public and private network decreased by $6 \%$. There was an increase in enrollment of ordinary classes of mainstream education for all categories analyzed, $20 \%$ of total enrollment, $21 \%$ in private schools, and $20 \%$ in public. Conclusions: The special education in Brazil has shown indications of being passed over the last few years by a transitional phase, adapting the proposed service models for the actors involved in the discussion of this issue around the world mainly through public education.

Keywords: Special education. Administrative responsibility. School inclusion. Brazil. 


\section{INTRODUÇÃO}

A educação especial no Brasil teve início em 1854 com o surgimento do instituto dos Meninos Cegos, sendo posteriormente ampliado o atendimento com a criação do Instituto dos Surdos-Mudos no ano de 1857 (MENDES, 2010). Porém nos anos que se seguiram, muito lento e pontual foi o desenvolvimento de novas instituições que propunham o atendimento frente aos sujeitos com necessidades especiais (MENDES, 2010).

Já na década de 1950, emerge movimento que protagonizou a constituição das Associações de Pais e Amigos dos Excepcionais (APAEs). Estas associações fomentaram a criação de inúmeros institutos de atendimento, sendo que seu ápice se deu nas décadas que se sucederam, ou seja, 1960 e 1970 (MENDES, 2010). Em contrapartida, na rede pública de educação, foi um período de ampliação das escolas especializadas e as classes especiais dentro de escolas regulares. Foi então, este período, de intensa institucionalização da educação na realidade brasileira (MIRANDA, 2004; FERREIRA, 1991; MENDES, 2010).

Posteriormente à Constituição brasileira de 1988, iniciou-se uma modificação no atendimento, através de uma perspectiva inclusiva, pois fica assegurada que a educação especial deveria ocorrer preferencialmente na rede regular de ensino, assim como, a realização de suporte adequado, com a oferta de atendimento educacional especializado (MENDES, 2010). Mesmo assim, levantamento de Ferreira (1989) demonstrou que ainda era precária a oferta de atendimento da educação especial nas décadas de 1970 e 1980, abarcando somente de 1,5\% a 2\% das matrículas. Mais que isto, 0 atendimento aos portadores de necessidades especiais era realizado através de instituições privadas, geralmente filantrópicas, e que não garantiam a escolarização, ou através de classes especiais em escolas regulares que mais excluíam os sujeitos e geravam segregação do que realizavam a escolarização (MENDES, 2010).

Mesmo com a legitimação de legislações favoráveis, continua-se sustentado até o início da década de 1990 a hegemonia do modelo de assistência separatista e excludente da educação, onde legitimava-se a segregação e a limitação da evolução do sujeito. Este cenário inicia mudança ao final da década com a crescente discussão da inclusão dos sujeitos nas classes comuns da rede regular (BRASIL, 1997; MENDES, 2010). Este ideal norteia a política atual, com a inclusão na rede regular e suporte de atendimento educacional especializado no turno inverso ao da escolarização (BRASIL, 2009; BRASIL, 2011).

Na perspectiva atual, é possivel observar através do trabalho realizado por Meireles, Freitas e Baptista (2015) que o Rio Grande do Sul alterou o panorama de atendimento entre os anos de 2007 e 2013, onde 
no início do período havia uma maior quantidade de matriculas da educação especial em instituições especializadas, enquanto que ao final inverteu-se, sendo a educação na rede regular à responsável pelo maior contingente de matrículas. Todavia, referente à dependência administrativa de origem de cada matrícula da educação especial, não houve retração dos números tanto para a rede pública quando para a privada, sendo observado maior proporção de matriculas ao longo de todo o período na rede privada (Meireles, Freitas e Baptista, 2015).

Já em Santa Catarina, ao ser abordado o período entre 2005 e 2009 foi observado retração nas matrículas da rede privada, e aumento na rede pública. Diferentemente do retrato tido no início do período abordado, ao final a educação pública abarcava o maior contingente de matrículas da educação especial (BASSI, 2015). Este fenômeno parece estar associado ao maior aporte financeiro disponibilizado para a indução da inclusão dos educandos portadores de necessidades especiais através da rede pública (BASSI, 2015).

Tendo em vista as nuanças da evolução do cenário da educação especial, e a perspectiva atual de ideal através do incentivo público para a inclusão dos educandos em classes comuns do ensino regular, este estudo teve como objetivo avaliar a evolução do atendimento educacional no Brasil segundo a dependência administrativa das instituiç̧ões educacionais, utilizando-se como subsídio para a análise e discussão, a quantidade de matrículas registradas junto ao Censo Educacional entre os anos de 2005 e 2013.

\section{MÉTODO}

Estudo ecológico baseado em uma série histórica de dados referentes a dados secundários oriundos de matrículas de educação provenientes dos Censos Educacionais entre os anos de 2005 e 2013 e que são disponibilizados pelo Instituto Nacional de Estudos e Pesquisas Educacionais Anísio Teixeira (INEP), através do endereço eletrônico http://portal.inep. gov.br. Os dados referem-se às matrículas realizadas em todo o território brasileiro e incluem instituições tanto da rede pública quanto da rede privada de ensino.

Os dados foram coletados no decorrer do mês de novembro de 2014, sendo realizado o download do Censo Educacional de cada ano com seus respectivos arquivos. Foi extraído da sinopse de cada ano os dados referentes às quantidades de matrículas na educação básica, e na educação especial; assim como a estratificação destes dados para o tipo de dependência administrativa (pública ou privada) de cada instituição. 
Após extraídos, os dados foram alocados em tabelas dentro de planilhas criadas através do programa Microsoft Office Excel 2013. Posteriormente, os dados foram transferidos para o programa Stata 11.0 onde foram analisados empregando: Correlação de Spearman, Regressão de Poisson robusta, e Intervalo de Confiança de 95\%. O nível de significância empregado foi de $p<0,001$.

\section{ASPECTOS ÉTICOS}

O estudo aqui apresentado, contou com a utilização de dados de domínio público, ou seja, dados secundários. No momento da coleta de dados, as informações estavam disponíveis no endereço eletrônico: http://portal.inep. gov.br. Estes dados são disponibilizados pelo Ministério da Educação através do Instituto Nacional de Estudos e Pesquisas Educacionais Anísio Teixeira (INPE). Tendo em vista a origem dos dados e sua disponibilização à população, não se identifica a necessidade de apreciação do presente estudo por comitê de ética em pesquisa.

\section{RESULTADOS}

Este estudo analisou 474.365.923 matrículas da educação básica brasileira, sendo que, referente à dependência administrativa da instituição onde está alocada a matrícula, 67.984.923 provêm da rede privada de ensino enquanto que 406.381 .000 da rede pública. Estratificando-se as matrículas da rede pública, 217.351.493 são da rede municipal, 187.010.130 da rede estadual, e 2.019.377 da rede federal.

As matrículas da educação básica foram em média 52.707.324,8 ( $\mathrm{DP}=2.268 .120$ ) inscrições por ano, com maior proporção ocorrendo no ano de 205 e o menor no ano de 2013. As médias para rede privada e pública foram de respectivamente 7.553.880 (DP=663970,1) e 474.011,4 (DP= 151.398,3). A evolução das matriculas totais da educação básica é apresentada no Gráfico 1.

Para a educação especial, foram observadas que 6.113 .533 de matrículas foram caraterizadas dentro deste espectro. Em relação à dependência administrativa, 1.847.358 eram da rede privada e 4.266.103 da rede pública. Da rede pública, 12.876 são de instituições federais, 1.573.922 de estaduais, e 4.266.103 de municipais. As matrículas da educação especial foram em média 679.281,4 (DP=121.400,6) por ano, sendo, $205.262(D P=36722,4)$ para rede privada, enquanto que 474.011,4 ( $D P=151.398,3)$ para rede pública. A evolução das matrículas totais para a educação especial, assim como para cada rede de ensino, é apresentada no Gráfico 2. 


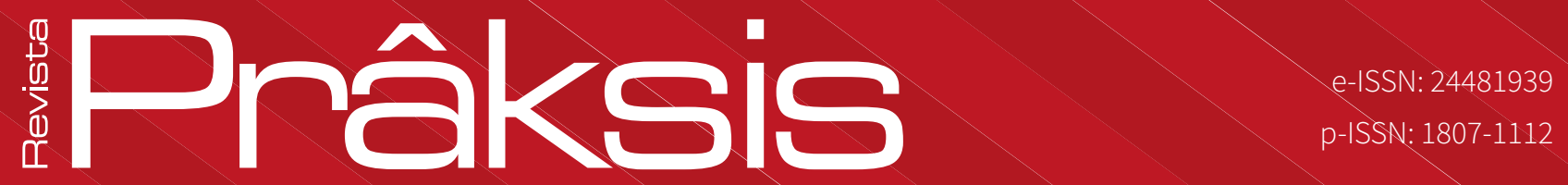

Gráfico 1 - Matrículas na educação básica entre 2005 e 2013 no Brasil por dependência administrativa das instituições educacionais

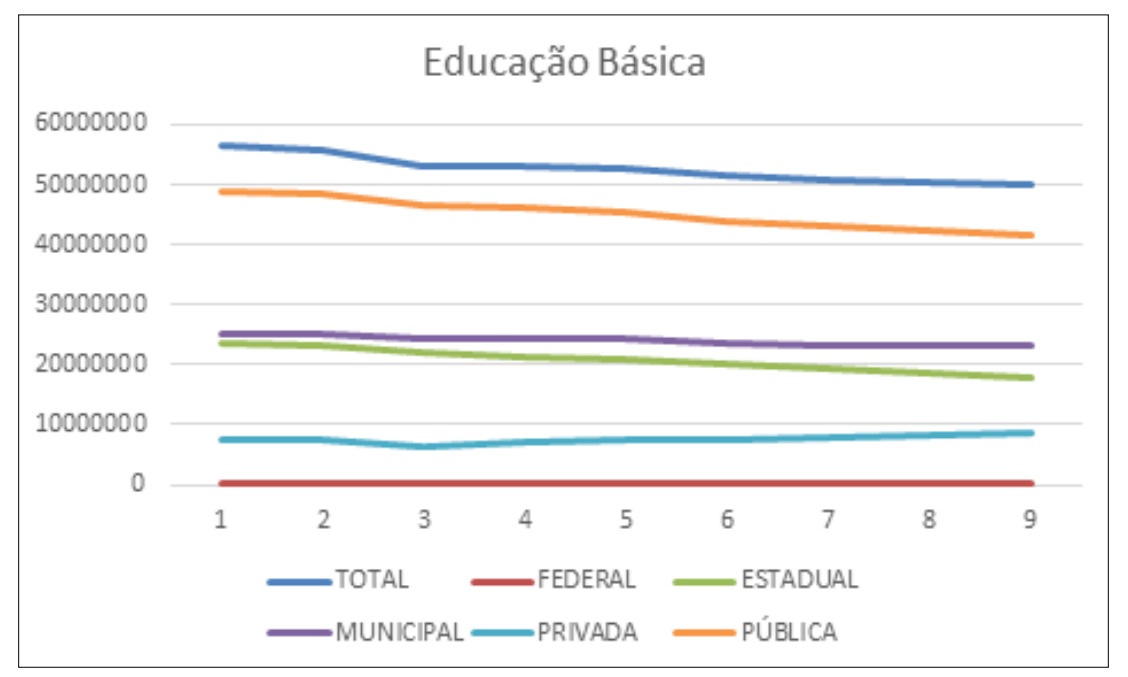

Fonte: Elaborado pelos autores

Gráfico 2 - Matrículas na educação especial entre 2005 e 2013 no Brasil por dependência administrativa das instituições educacionais

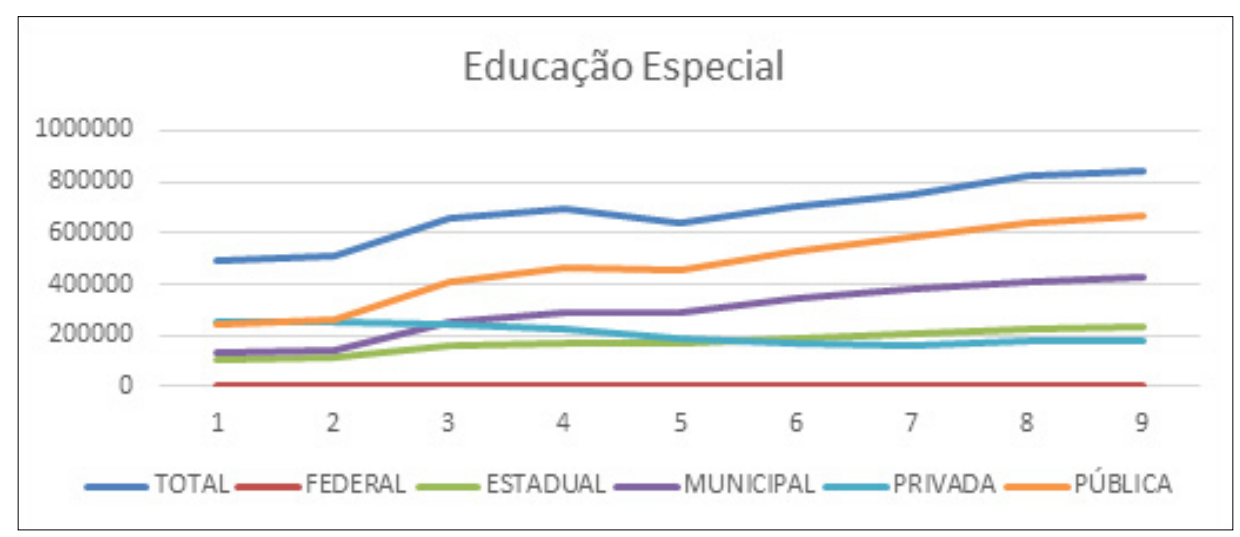

Fonte: Elaborado pelos autores

Especificamente sobre a modalidade de atendimento em escola especializada, foram ao total 1.979.363 matrículas, destas, 1.589.950 da rede privada e 389.411 da rede pública, destes últimos, 7.165 de instituições federais, 186.385 de estaduais, e 195.861 de municipais. A média anual de inscrições em 
escola exclusivamente especializadas foi de 219.929,2 (DP=60.301) sendo 176.661,1 (DP=46300,6) matrículas por ano na rede privada e 43.267,9 (DP=14.099,9) na rede pública. A evolução das matrículas em Escolas Especializadas da educação especial é apresentada no Gráfico 3.

\section{Gráfico 3 - Matrículas em escola especializada do ensino especial entre 2005 e 2013 no Brasil por dependência administrativa das instituições educacionais}

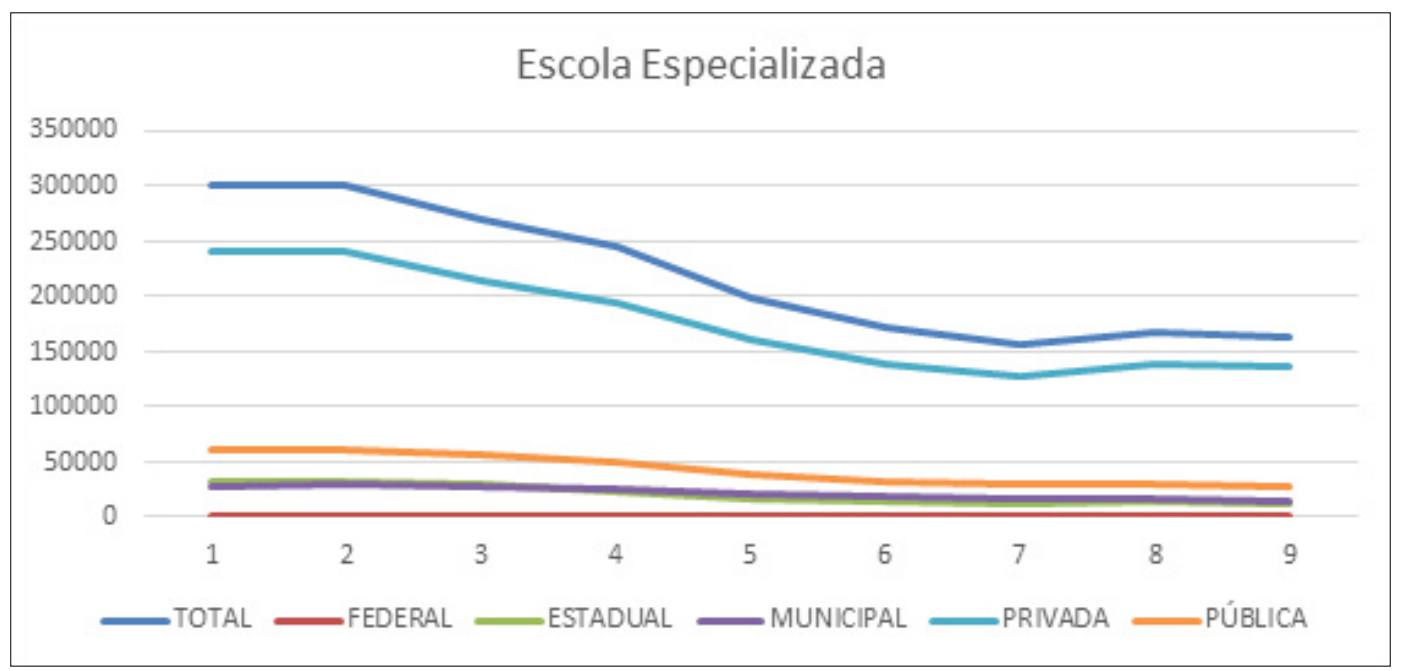

Fonte: Elaborado pelos autores

Nas classes especiais de escolas regulares, foram ao total 501.510 matrículas, com 45.002 da rede privada e 456.508 da rede pública. Mais especificamente, 128 matrículas de instituições federais, 173.310 de estaduais, e 283.070 de municipais. A média de matrículas nesta modalidade de atendimento foi de 55.723,3 ( $\mathrm{DP}=20218,5)$ inscrições por ano, já ao se estratificar, observou-se os seguintes valores: $5.000,2(\mathrm{DP}=3165,4)$ para a rede privada e 50.723,1 (DP=18856,6) para rede privada. A evolução das matrículas em Classe Especial em escola regular é apresentada no Gráfico 4.

As matrículas para classe comum de escola regular totalizou ao longo do período 3.632 .660 matriculas, sendo 212.406 da rede privada, e 3.420 .184 da rede pública. Da rede pública, 5.583 de instituições federais, 1.214.227 de estaduais, e 2.200.374 de municipais. Observou-se em média 403.628,9 (DP= 194.662,9) matriculas por ano, sendo em média 23.600,7 ( $\mathrm{DP}=12.035,6)$ na rede privada e 380.020,4 (DP=182.694,9) na rede pública. A evolução das matrículas em classe comum de escola regular é apresentada no Gráfico 5. 
Ao longo do período estudado, observou-se diminuição significativa das matrículas totais da educação básica em $2 \%$, redução observada também para a rede pública em $2 \%$, e dentro desta nas instituições municipais em $1 \%$ nas estaduais em $4 \%$. Não houve modificação significativa nas matrículas da rede privada $(p=0,002)$, e houve aumento no número das matrículas para as instituições federais na rede pública de ensino em $7 \%$.

Especificamente sobre as matrículas da educação especial, diferentemente da educação básica, houve aumento em $6 \%$. Aumento evidenciado na rede pública $12 \%$, e dentro desta, $11 \%$ em instituições federais, $9 \%$ de estaduais e $14 \%$ de municipais. Em contrapartida, houve diminuição na rede privada em $6 \%$ das matrículas.

Em relação à modalidade de atendimento foi evidenciada redução do número de matrículas em escola especializada em todas as categorias de estratificação avaliadas, com percentuais variando entre $3 \%$ e 13\%. Já nas classes especiais houve retração nas matrículas totais em $12 \%$ e na rede pública em 13\%, não sendo observada variação significativa para rede privada.

Por fim, referente às classes comuns em escola regular houve aumento em todas as categorias analisadas, sendo $20 \%$ nas matrículas totais, $21 \%$ na rede privada, e 20\% na rede pública. Destas últimas, houve aumento de $34 \%$ em instituições federais, 19\% em estaduais, e 20\% em municipais.

\section{Gráfico 4 - Matrículas em classe especial em escola regular entre 2005 e 2013 no Brasil por dependência administrativa das instituições educacionais}

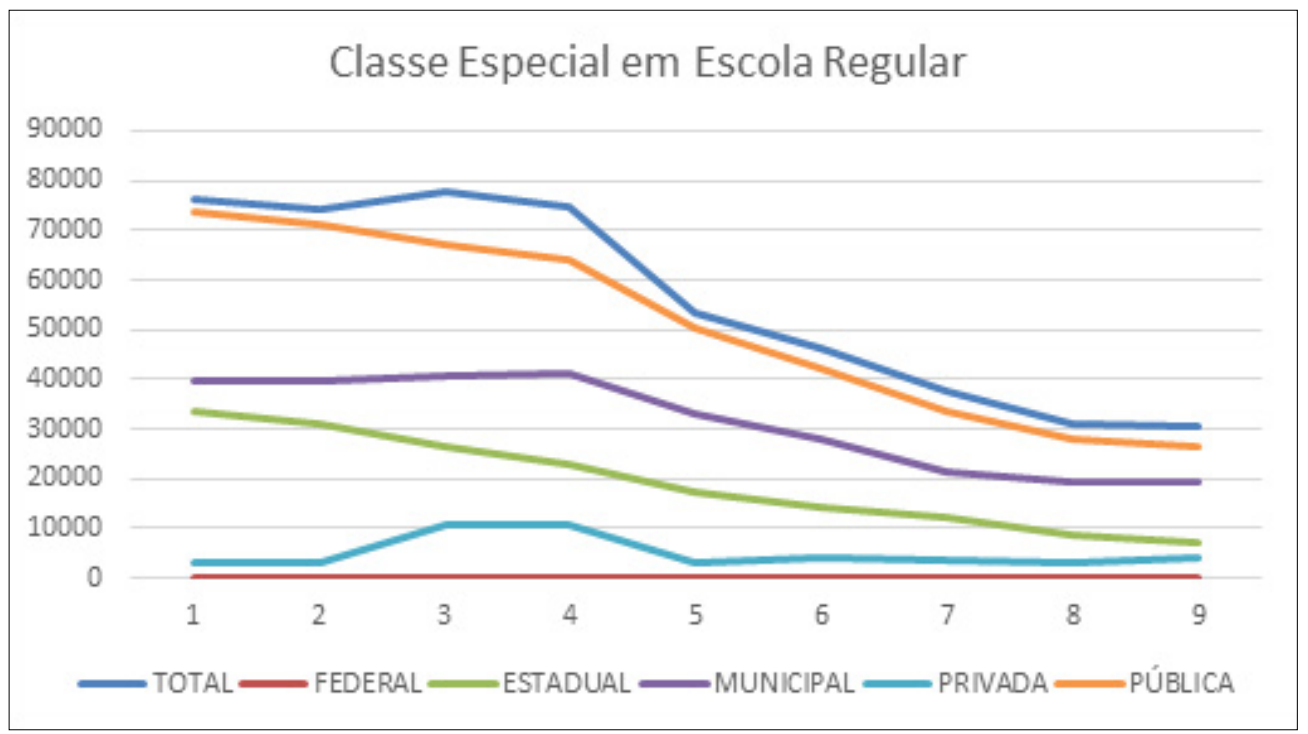

Fonte: Elaborado pelos autores 


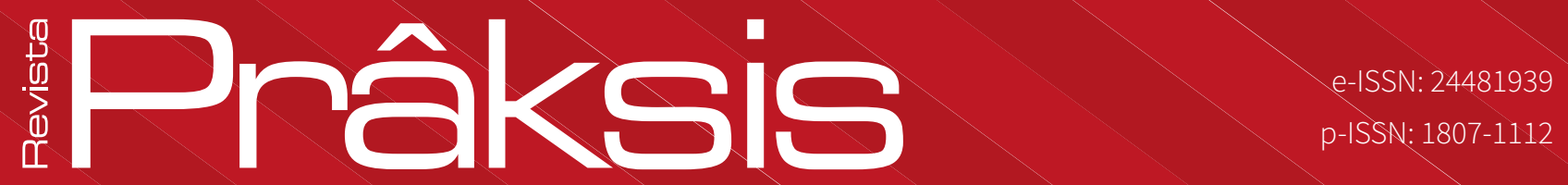

Gráfico 5 - Matrículas em classe comum em escola regular entre 2005 e 2013 no Brasil por dependência administrativa das instituições educacionais

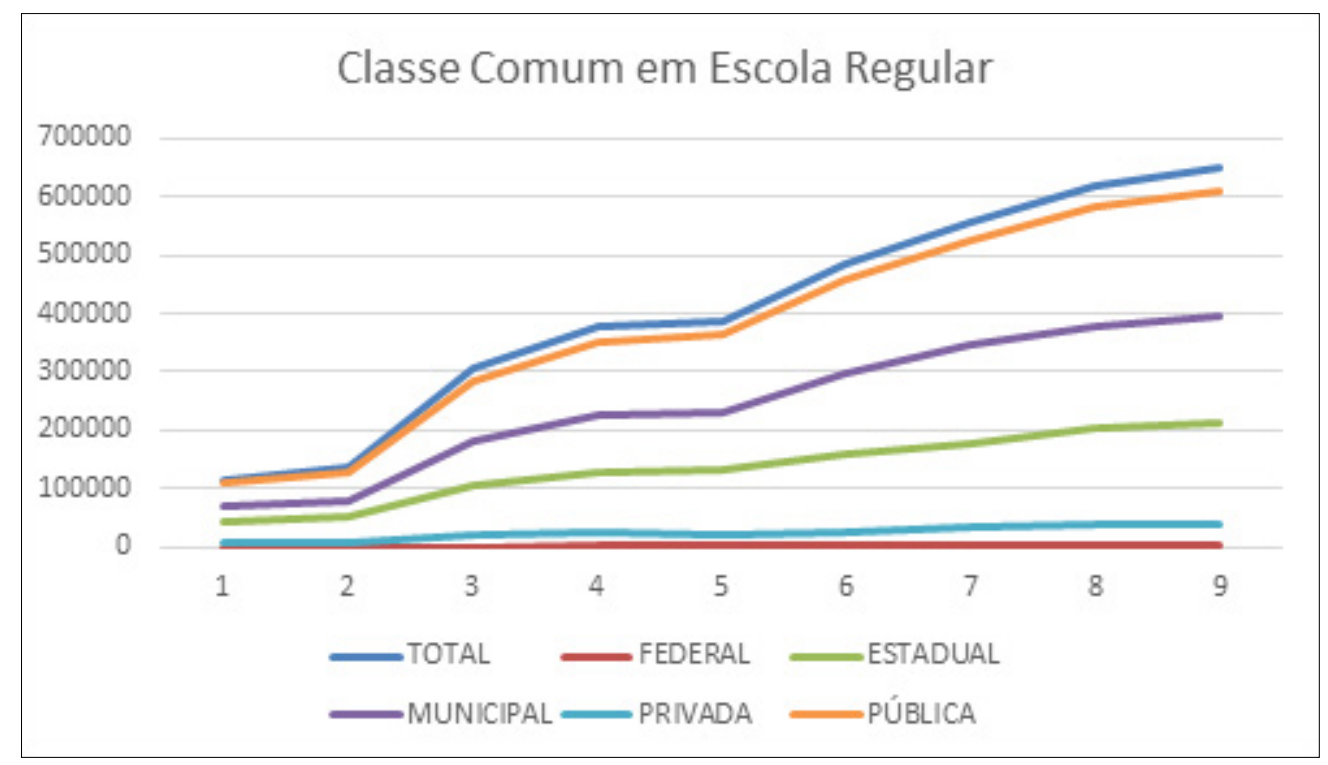

Fonte: Elaborado pelos autores

Tabela 1 - Análise através da Regressão de Poisson robusta da evolução das matrículas entre 2005 e 2013 no Brasil

\begin{tabular}{lc|c|c}
\hline Variável & RP & IC 95\% & P \\
\hline No de inscrições na Educação Básica & & & \\
Total & 0,98 & $0,98-0,99$ & $<0,001$ \\
Federal & 1,07 & $1,06-1,08$ & $<0,001$ \\
Estadual & 0,96 & $0,96-0,97$ & $<0,001$ \\
Municipal & 0,99 & $0,99-0,99$ & $<0,001$ \\
Particular & 1,02 & $1,01-1,04$ & 0,002 \\
Pública & 0,98 & $0,98-0,98$ & $<0,001$ \\
\hline
\end{tabular}


(continuação)

\begin{tabular}{|c|c|c|c|c|}
\hline Variável & & RP & IC $95 \%$ & $\mathbf{p}$ \\
\hline \multicolumn{5}{|c|}{$N^{\circ}$ de inscrições no Ensino Especial } \\
\hline & Total & 1,06 & $1,04-1,08$ & $<0,001$ \\
\hline & Federal & 1,11 & $1,09-1,12$ & $<0,001$ \\
\hline & Estadual & 1,09 & $1,07-1,12$ & $<0,001$ \\
\hline & Municipal & 1,14 & $1,10-1,18$ & $<0,001$ \\
\hline & Particular & 0,94 & $0,93-0,96$ & $<0,001$ \\
\hline & Pública & 1,12 & $1,09-1,16$ & $<0,001$ \\
\hline \multicolumn{5}{|c|}{$N^{\circ}$ de inscrições em Escola Especializada } \\
\hline & Total & 0,91 & $0,89-0,93$ & $<0,001$ \\
\hline & Federal & 0,97 & $0,97-0,96$ & $<0,001$ \\
\hline & Estadual & 0,87 & $0,84-0,89$ & $<0,001$ \\
\hline & Municipal & 0,91 & $0,89-0,92$ & $<0,001$ \\
\hline & Particular & 0,91 & $0,89-0,93$ & $<0,001$ \\
\hline & Pública & 0,89 & $0,87-0,91$ & $<0,001$ \\
\hline
\end{tabular}

$N^{\circ}$ de inscrições em Classe Especial

$\begin{array}{rccc}\text { Total } & 0,88 & 0,85-0,91 & <0,001 \\ \text { Federal } & 0,97 & 0,66-1,42 & 0,872 \\ \text { Estadual } & 0,82 & 0,81-0,84 & <0,001 \\ \text { Municipal } & 0,90 & 0,87-0,93 & <0,001 \\ \text { Particular } & 0,95 & 0,84-1,07 & 0,393 \\ \text { Pública } & 0,87 & 0,85-0,89 & <0,001\end{array}$

$N^{\circ}$ de inscrições em Classe Comum

\begin{tabular}{rrrr} 
Total & 1,20 & $1,13-1,27$ & $<0,001$ \\
Federal & 1,34 & $1,27-1,41$ & $<0,001$ \\
\hline
\end{tabular}


(conclusão)

\begin{tabular}{rr|r|c}
\hline Variável & RP & IC 95\% & P \\
\hline Estadual & 1,19 & $1,13-1,25$ & $<0,001$ \\
Municipal & 1,20 & $1,14-1,27$ & $<0,001$ \\
Particular & 1,21 & $1,12-1,30$ & $<0,001$ \\
Pública & 1,20 & $1,13-1,27$ & $<0,001$ \\
\hline
\end{tabular}

Fonte: Elaborado pelos autores

O total de matrículas na Educação Básica se correlacionou inversamente com o Total das matrículas na Educação Especial. Já, referente especificamente à Educação Especial, não observou-se correlação significativa entre as matrículas entre a rede pública e a rede privada. Houve sim, correlação significativa, porém inversa, entre as matriculas totais em Escolas Especializadas e aquelas em Classe Comum em escola regular, assim como entre as inscrições em Classe especial de escola regular e em Classe comum também em escola regular. Por fim, não houve correlação entre as inscrições em Escolas Especializadas e em Classe Especial. As correlações são apresentadas na Tabela 2.

Tabela 2 - Análise através da Correlação de Spearman entre os totais de matrículas por dependência administrativa da instituição educacional no Brasil

\begin{tabular}{l|cc}
\hline & Spearman`s rho & p \\
\hline Inscrições no Ensino Especial (Pública) x Inscrições no Ensino Especial (Particular) & $-0,817$ & 0,007 \\
Inscrições na Educação básica (Total) x Inscrições no Ensino Especial (Total) & $-0,933<0,001$ \\
Inscrições em Escola Especializada (Total) x Inscrições em Classe Comum & $-0,950$ & $<0,001$ \\
Inscrições em Classe Especial (Total) x Inscrições em Classe Comum & $-0,917$ & $<0,001$ \\
Inscrições em Escola Especializada (Total) x Inscrições em Classe Especial & 0,867 & 0,002 \\
\hline
\end{tabular}

Fonte: Elaborado pelos autores 


\section{DISCUSSÃO}

A educação em uma perspectiva ampla (total da Educação Básica), tem demonstrado retração em sua quantidade de matrículas, o que reflete uma modificação no perfil demográfico da população brasileira. Há, deste modo, um menor número de sujeitos dentro das idades, onde, de praxe se desenvolve a escolarização. Esta concepção corrobora com os levantamentos demográficos desenvolvidos e disponíveis pelo Ministério da Saúde através do domínio eletrônico do DataSUS, onde em 2005 a população em idade escolar (com grupos etários aproximados entre 5 e 19 anos) era de 56.261.170 habitantes, enquanto que em 2012 esta estimativa foi de 49.978.361 habitantes.

Em contrapartida, a Educação Especial apresentou acréscimo em seu número de sujeitos em atendimento especializado para os sujeitos com necessidades educacionais especiais. Este fato parece refletir de um lado um maior rastreamento e diagnóstico de sujeitos que necessitam de suporte adicional, e de outro, um rearranjo organizacional (político e de recursos) que favoreceram o atendimento destes sujeitos. Não sendo então, um acompanhamento da modificação demográfica da população em geral.

É importante ressaltar que a proporção de crescimento da Educação Especial se deu em função da positiva evolução da rede de atendimento pública, pois a rede privada apresentou retração no total de matriculas ao longo do período. Este dado reforça a efetividade das políticas públicas desenvolvidas no Brasil ao longo das últimas décadas e do maior aporte financeiro disponibilizado para a indução da inclusão dos educandos portadores de necessidades especiais através da rede pública (BASSI, 2015).

A retração das matrículas na rede privada se deu pela redução nas matrículas em Escolas Especializadas. Em contrapartida, as matrículas em classe comum em escola regular tiveram elevação para a rede privada. Este fato nos leva a pensar que as instituições de educação privada estão buscando evoluir conforme preconizado pelos ideais comungados pela sociedade e consolidados em diferentes momentos como na Declaração de Salamanca (BRASIL, 1997).

As instituições educacionais com dependência administrativa pública também evoluíram em consonância ao proposto e acordado entre Salamanca pelos Governantes brasileiros. Nestes últimos 8 anos, foi ampliada a oferta e o atendimento através da inclusão em classes comuns de escolares regulares, diminuindo-se assim a segregação fomento do preconceito que ocorria através dos atendimentos em classes especiais ou escolas especializadas (escolas especiais) (MENDES, 2010). 
Aparece ainda importante a avaliação da qualidade dos serviços prestados, pois a ampliação da oferta não necessariamente garante a qualidade do atendimento. É relevante sim, e muito almejado, a universalidade do atendimento à totalidade dos sujeitos que necessitem, mas espera-se, que este atendimento não seja apenas um cumprimento legal e auxilie o desenvolvimento dos sujeitos.

\section{CONSIDERAÇÕES FINAIS}

A educação especial no Brasil, tem demonstrado indicativos de estar passado ao longo dos últimos anos por uma fase de transição, adequando-se aos modelos de atendimento propostos pelos atores implicados na discussão desta temática ao redor do mundo. Há então a transposição dos alunos, de modalidades segregantes, e que geram a exclusão, para modelos que propiciam a integração dos sujeitos e consequentemente sua inclusão social.

É observado, principalmente através do setor público, uma importe preocupação com a disponibilização de suporte especializado aos sujeitos que necessitam. Este fenômeno é exaltado através da ampliação da quantidade de vagas para a educação especial. Ainda assim, a rede privada de educação permanece detendo um percentual importante de sujeitos, e, assim como o setor público, tem ampliado o atendimento através de classes comuns do ensino regular.

Parece importante a continuidade dos aspectos desencadeantes implicados na alteração do modelo de atendimento que estão em andamento visando assim a consolidação do modelo considerado na atualidade o mais inclusivo (classes comuns do ensino regular). Mais que isto, deve-se desenvolver um olhar mais atento à rede privada, propondo-se meios que fomentem nas instituições pertencentes à esta, a busca da ampliação dos processos inclusivos. 


\section{REFERÊNCIAS}

BASSI, Marcos Edgar. Políticas de financiamento e inclusão no atendimento público de educação especial no estado de Santa Catarina. In: BAPTISTA, Claudio Roberto (Org.).

Escolarização e deficiência: configurações nas políticas de inclusão escolar. São Carlos: Marquezine \& Manzini/ABPEE, 2015.

BRASIL, Presidência da República, Secretaria Especial dos Direitos Humanos. Declaração de Salamanca e linha de ação sobre necessidades educativas especiais. Brasília, DF: Coordenadoria Nacional para Integração da Pessoa Portadora de Deficiência - CORDE, 1997.

BRASIL, Ministério da educação. Resolução n 4, de 2 de outubro de 2009. Institui diretrizes operacionais para o atendimento educacional especializado na educação básica, modalidade educação especial. Brasília, DF: 2009.

BRASIL, Presidência da República, Casa civil. Decreto n7.611, de 17 de novembro de 2011. Dispõe sobre a educação especial, o atendimento educacional especializado e dá outras providências. Brasília, DF: 2011.

FERREIRA, Júlio Romero. Notas sobre a evolução dos serviços de educação especial no Brasil. Revista Brasileira de Educação Especial. Relatório de atividades da XIV Reunião. Boletim ANPed, 1-2, 1991.

MEIRELLES, Melina Chassot Benincasa; FREITAS, Cláudia Rodrigues; BAPTISTA, Claudio Roberto. Educação especial no Rio Grande do Sul: Uma análise de indicadores de matrículas na educação básica (2007-2013). In: BAPTISTA, Claudio Roberto (Org.). Escolarização e deficiência: configurações nas políticas de inclusão escolar. São Carlos: Marquezine \& Manzini/ ABPEE, 2015.

MENDES, Enicéia Gonçalves. Breve histórico da educação especial no Brasil. Revista Educación y Pedagogía, v. 22, n. 57, 2010.

MIRANDA, Arlete Aparecida Bertoldo. História, deficiência e educação especial. Revista HISTEDBR On-line, 2004. 